\title{
Comparative Study between the Efficacy of Amantadine Sulphate versus Erythropoietin on Traumatic Brain Injury
}

\author{
MAHMOUD E. EL-TOOKHY, M.Sc.; MOHAMMAD E. OKAB, M.D.; SABRY M. AMEEN, M.D. and \\ ASMAA F. AMER, M.D.
}

The Department of Anesthesiology and Surgical Intensive Care, Faculty of Medicine, Tanta University, Tanta, Egypt

\begin{abstract}
Background: Traumatic Brain Injury (TBI) is the most common cause of death and disability. Improvement of recovery is a challenging process in cases with varying degrees of severe brain injury requiring intensive care. Fortunately, a number of pharmacological interventions show promise in helping patients cope with these losses and deficits. Medications may be used to support recovery, Examples are Erythropoietin (EPO) and Antiparkinsonian drugs (Amantadine Sulphate).
\end{abstract}

Aim: To compare the efficacy of Amantadine Sulphate versus Erythropoietin on improvement of traumatic brain injury outcome.

Material and Methods: This study was carried out on three equal groups each group consist of 20 patients according to sample size calculation based on the fact, whether they received or didn't receive Amantadine Sulphate or Erythropoietin in addition to standard therapy.

Group I (Amantadine Group): Patients were received Amantadine Sulphate in dose of $200 \mathrm{mg}$ twice daily intravenous (IV) at 9:00am and 3:00pm for 1 week, from 3 rd day of hospitalization then oral Amantadine Sulphate 200mg twice daily for 3 weeks in addition to standard therapy.

Group II (Erythropoietin Group): Patients received Erythropoietin subcutaneously (SC) from $3^{\mathrm{r}} \mathrm{d}$ day of injury 40,000 International Units (IU) once per week for maximum 3 doses at day 3,10 and 17 including standard therapy.

Group III (Control Group): Patients received placebo ( $0.9 \%$ saline) for 4 weeks (standard therapy only). The following measurements were recorded: Glasgow Coma Scale (GSC), Disability Rating Scale (DRS), Sedation scale, length of mechanical ventilation, length of surgical ICU stay, hospital stay and complications.

Results: In the group of patients with severe brain injuries treated with standard therapy plus Amantadine Sulphate, consciousness was better, the case fatality rate was lower and length of mechanical ventilation, SICU stay and hospital stay were shorter than in the group treated with standard therapy

Correspondence to: Dr. Mahmoud E. El-Tookhy, The Department of Anesthesiology and Surgical Intensive Care, Faculty of Medicine, Tanta University, Tanta, Egypt plus Erythropoietin and the group treated with standard therapy only.

Conclusions: Using of Amantadine Sulphate is better than using of Erythropoietin for improving neurorecovery on Traumatic Brain Injury (TBI), also we concluded that Erythropoietin is a potentially useful treatment option for TBI but confirmatory evidence is required for that and for the ability of EPO to increase the risk of Venous Thromboembolism (VTE).

Key Words: Traumatic brain injury - Amantadine Sulphate - Erythropoietin.

Key Message: Amantadine Sulphate is better than Erythropoietin for improving neurorecovery on traumatic brain injury (TBI).

\section{Introduction}

TRAUMATIC Brain Injury (TBI) is the most common cause of death and disability in persons between 15 and 30 years of age. TBI is the most serious and preventable major public health problem [1]. Improvement of recovery is a challenging process in cases with varying degrees of severe brain injury requiring intensive care [2].

Fortunately, a number of pharmacological interventions show promise in helping patients cope with these losses and deficits. Medications may be used to support recovery, Examples are Erythropoietin (EPO) and Antiparkinsonian drugs (Amantadine Sulphate) [3]. Amantadine Sulphate is a reasonable option for improving cognition and reducing agitation following a TBI. Amantadine is one of the most commonly prescribed medications for patients with prolonged disorders of consciousness after traumatic brain injury [4].

Preliminary studies have suggested that amantadine may promote functional recovery [5]. As regard Erythropoietin (EPO), many studies results confirmed that EPO is endogenous cytokines of 
the central nervous system, and play a neurotrophic and neuroprotective role [6] .

EPO has effects, independent of those on erythropoiesis, which are relevant to patients who have had a TBI. EPO crosses the blood-brain barrier and targets multiple mechanisms known to cause secondary injury after TBI, including antiedematous, anti-excitotoxic, antioxidant, antiapoptotic activity, anti-inflammatory mechanisms activity and protective neurological effects in the presence of hypoxia and ischemia [7].

\section{Aim and objectives:}

The aim of the study is to compare the efficacy of Amantadine Sulphate versus Erythropoietin on improvement of traumatic brain injury outcome.

\section{Material and Methods}

After obtaining the Research Ethics Committee approval and informed written consent was taken from patient guardians, a prospective randomized clinical trial was carried out in Tanta University Hospitals at Surgical Intensive Care Unit (SICU) for six months between July 2016 to December 2016,60 patients of (GCS $<8$ ), aged from (18-65 years) of both sex admitted to SICU were enrolled in the study. Refusal of patient guardians, bleeding disorders, subjects who had any type of penetrating head injury, severe pre-existing physical or mental disability or severe co-morbidity that could interfere with the assessment of outcome, polytrauma patients, pregnancy, history of DVT, PE or other thromboembolic event, prior significant TBI, brain tumor, cerebral vascular event, or other stable brain insult and hemodynamically unstable patient were excluded from the study.

Patients were randomly classified using closed sealed envelope into three equal groups each group consist of 20 patients according to sample size calculation, as follow: Group I (Amantadine Group): Patients were received Amantadine Sulphate in dose of $200 \mathrm{mg}$ twice daily Intravenous (IV) at 9:00am and 3:00pm for 1 week from $3 \mathrm{rd}$ day of hospitalization, then oral Amantadine Sulphate $200 \mathrm{mg}$ twice daily for 3 weeks in addition to standard therapy. Group II (Erythropoietin Group): Patients were received Erythropoietin Subcutaneously (SC) from 3 rd day of injury 40,000 International Units (IU) once per week for maximum 3 doses at day 3,10 and 17 in addition to standard therapy. Group III (Control Group): Patients were received placebo ( $0.9 \%$ saline) for 4 weeks (standard therapy only).
Prior to arrival to the SICU, patients with severe TBI were usually received, resuscitated and stabilized in Emergency Department or operating room. Once the severely head-injured patient has been transferred to the SICU, the management consists of the provision of high quality general care and various strategies aimed at maintaining hemostasis with stabilization of the patient, if still unstable, prevention of intracranial hypertension, maintenance of an adequate and stable Cerebral Perfusion Pressure (CPP), Avoidance of systemic, secondary brain insults (SBI) and optimization of cerebral hemodynamic and oxygenation.

Monitoring: Monitoring of patients with severe TBI is essential for the guidance and optimization of therapy. The rationale of monitoring is early detection and diagnosis of secondary brain insults, both systemic and intracranial. During neurointensive care of patients with severe TBI, general parameters that are regularly monitored (Routine ICU monitoring) including electrocardiography (ECG monitoring), arterial oxygen saturation (pulse oximetry, $\mathrm{SpO}_{2}$ ), capnography (end-tidal $\mathrm{CO} 2$, $\mathrm{PetCO} 2$ ), arterial blood pressure (arterial catheter), Central Venous Pressure (CVP), systemic temperature and urine output. Early tracheostomy done to patients expected to be ventilated more than 10 days or after failure of extubation trial.

Patients were managed according to our established treatment guidelines (our standard treatment protocol), including treatment of increased intracranial pressure and other medical treatments, which did not vary among neurosurgeons. Laboratory: Routine laboratory investigations, including liver and kidney functions, CBC, Blood sugar and coagulation profile. Radiological Examination: Doppler ultrasound for DVT every 3days during hospital stay.

Measurements: Glasgow Coma Scale (GCS), (Table 1), Disability Rating Scale (DRS), (Table 2), and sedation scale, (Table 3), were measured in patients on admission ( 1 st day of trauma) and repeated daily during $1{ }^{\text {st }}$ week, every 3 days during 2 nd week then monthly for 5 months, also length of mechanical ventilation, length of surgical ICU stay, hospital stay and complications were measured.

Data were coded and entered using the statistical package SPSS. Data was summarized using mean, standard deviation, median, minimum and maximum.

Comparisons between groups were done using the non-parametric Mann-Whitney test. Compari- 
son between values measured were done using the non-parametric Wilcoxon signed rank test. For comparing categorical data, Chi square $\left(\mathrm{X}^{2}\right)$ test was performed. $p$-values less than 0.05 were considered as statistically significant.

Table (1): Elements of the Glasgow Coma Scale [8].

\begin{tabular}{llc}
\hline Action & Response & Score \\
\hline Eye opening & Spontaneous & 4 \\
& To voice & 3 \\
& To pain & 2 \\
& No & 1 \\
Best verbal response & Oriented & 5 \\
& Confused & 4 \\
& Inappropriate words & 3 \\
& Incomprehensive sound & 2 \\
Best motor response & None & 1 \\
& Obeys & 6 \\
& Localize pain & 5 \\
& Withdrawal to pain & 4 \\
& Flexor posture & 3 \\
& Extensor posture & 1 \\
\hline
\end{tabular}

\section{Results}

Regarding the demographic data (age and sex) there was no significant difference between the three studied groups (Table 4).

In the current study, the following measurements Glasgow Coma Scale (GCS) (Table 5), Disability Rating Scale (DRS), Fig. (1), and Ramsay Sedation Scale (RSS), were recorded and the mean values showed that there was a statistically significant improvement in Group I compared to Group II and III. Also, the mean values showed insignificant improvement in Group II compared to Group III.

Regarding length of mechanical ventilation, there was no statistically significant difference between the three groups but it was shorter in Group I compared to Group II and III, as regard
Table (2): Disability Categories [9]

\begin{tabular}{ll}
\hline Total DR score & Level of disability \\
\hline 0 & None \\
1 & Mild \\
$2-3$ & Partial \\
$4-6$ & Moderate \\
$7-11$ & Moderately severe \\
$12-16$ & Severe \\
$17-21$ & Extremely severe \\
$22-24$ & Vegetative state \\
$25-29$ & Extreme Vegetative state \\
\hline
\end{tabular}

Table (3): Ramsay Sedation Score (RSS) [10]

\begin{tabular}{lc}
\hline Description & Score \\
\hline Anxious and agitated, or restless or both & 1 \\
Cooperative, oriented and tranquil & 2 \\
Responding to commands only & 3 \\
Brisk response to light glabellar tap or loud auditory stimulus & 4 \\
Sluggish response to light glabellar tap or loud auditory stimulus & 5 \\
No response to stimuli & 6 \\
\hline
\end{tabular}

to length of SICU stay, Fig. (2), and length of hospital stay, (Table 6), the mean values showed that there were statistically shorter in Group I compared to Group II and III.

In our study, seizures occurred in $10 \%$ of the patients ( 2 patients) in Group I as compared to 5\% of the patients ( 1 patient) in Group III. There were no seizures in Group II. There were no significant differences among three groups, deep vein thrombosis occurred in only 1 patient (5\% of the patients) in Group II. There was no DVT in Group I \& III. There was no pulmonary embolism in the three studied groups. As regard mortality rate, 4 patients died in Group I (20\%), 6 patients in Group II (30\%) and 7 patients in Group III (34\%). There were no significant differences among the three groups, (Table 7).

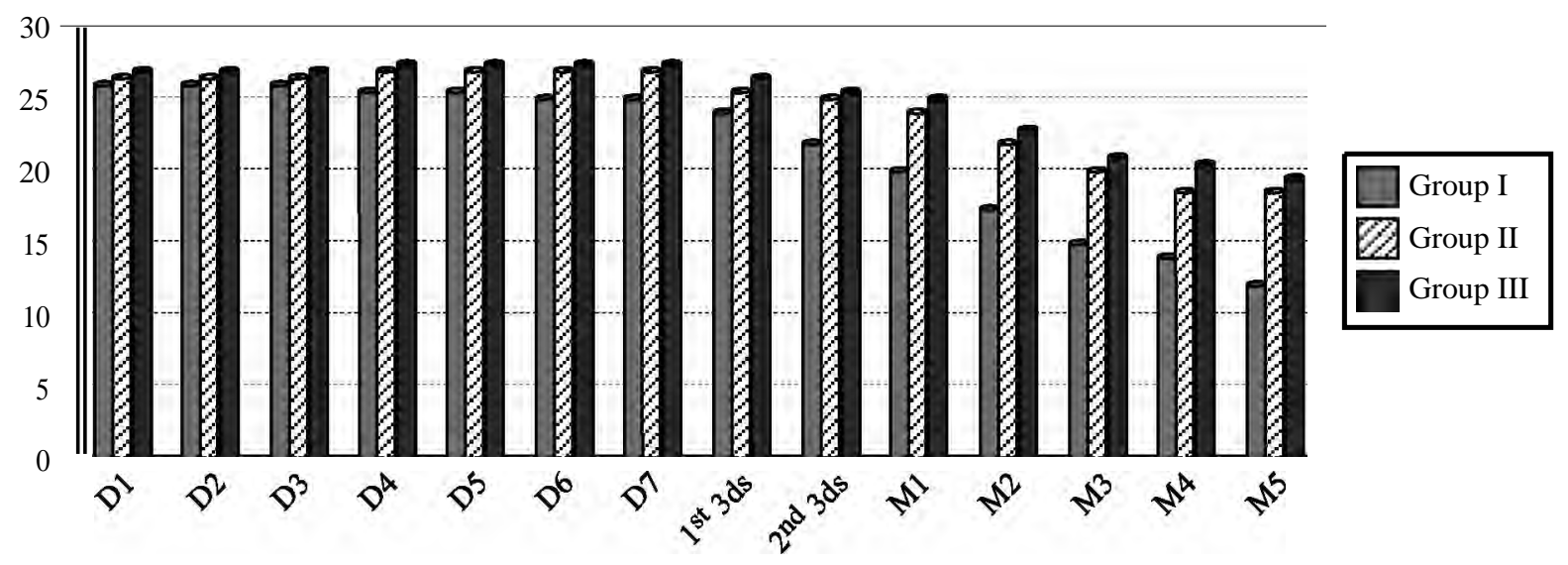

Fig. (1): Disability rating scale in the three groups. 


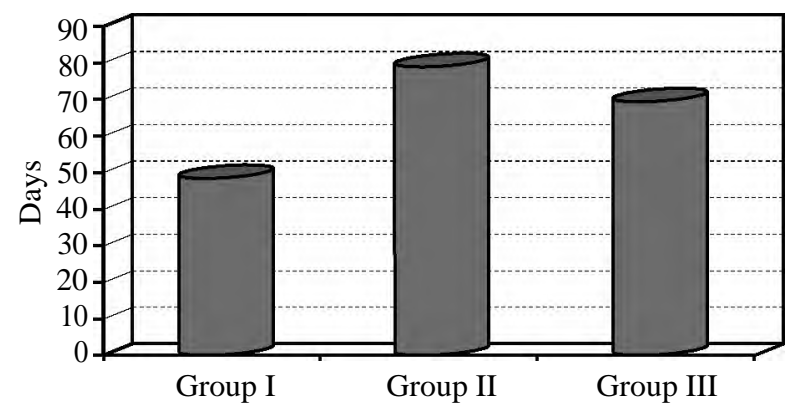

Table (4): Demographic data of patients in the three groups.

\begin{tabular}{|c|c|c|c|c|}
\hline Patient data & $\begin{array}{c}\text { Group I } \\
\mathrm{n}=20\end{array}$ & $\begin{array}{c}\text { Group II } \\
\mathrm{n}=20\end{array}$ & $\begin{array}{c}\text { Group III } \\
\mathrm{n}=20\end{array}$ & $\begin{array}{c}p- \\
\text { value }\end{array}$ \\
\hline $\begin{array}{l}\text { Age (years): } \\
\qquad(\text { Mean } \pm \mathrm{SD})\end{array}$ & $32.1 \pm 13.672$ & $33.3 \pm 12.049$ & $33.75 \pm 12.083$ & 0.912 \\
\hline $\begin{array}{r}\text { Gender: } \\
\text { (M:F) }\end{array}$ & $\begin{array}{ll}\mathrm{M}=17 & (85 \%) \\
\mathrm{F}=3 & (15 \%)\end{array}$ & $\begin{array}{l}\mathrm{M}=16(80 \%) \\
\mathrm{F}=4 \quad(20 \%)\end{array}$ & $\begin{array}{l}\mathrm{M}=18(90 \%) \\
\mathrm{F}=2 \quad(10 \%)\end{array}$ & 0.6756 \\
\hline
\end{tabular}

Fig. (2): Length of SICU (days) in the three groups.

Table (5): Glasgow coma scale in the three groups.

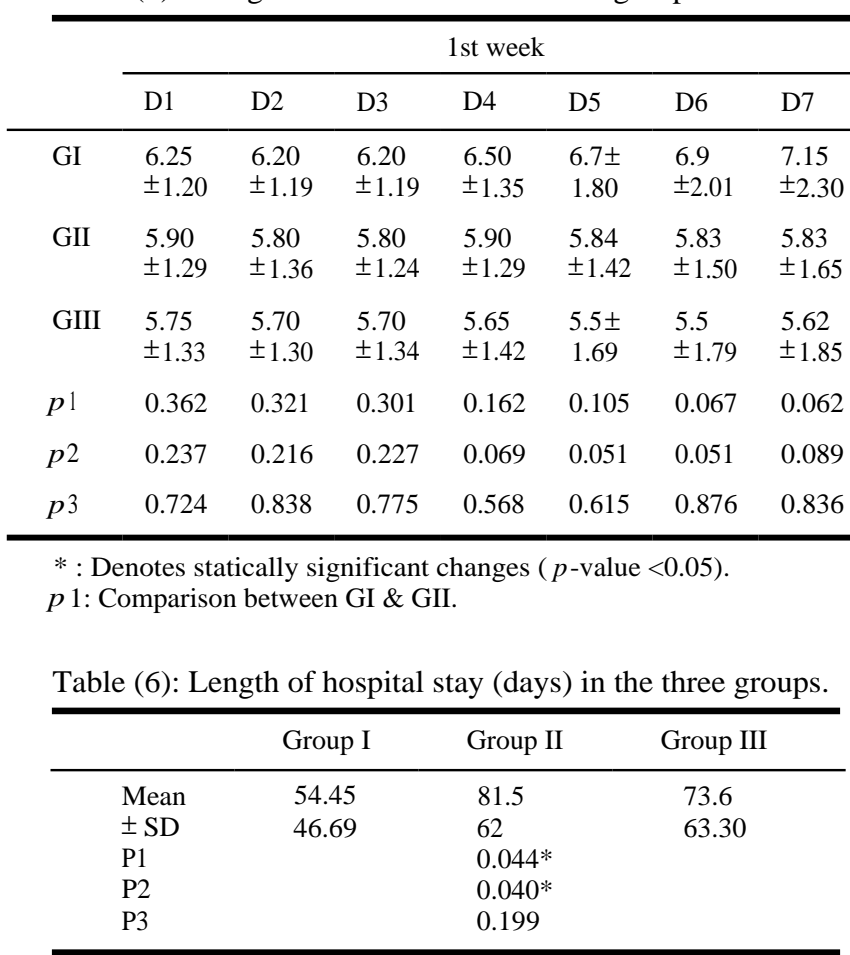

\section{Discussion}

Improvement of recovery is a challenging process in cases with varying degrees of severe brain injury requiring intensive care [11]

Both groups, Amantadine group and Erythropoietin Group showed improvement in conscious level guided by comparing the results of GCS, DRS and RSS at day 1 (baseline) and after five months and it was found that patients improved more while being on Amantadine Sulphate. In agreement with our results, a case report by Zafonte et al., [12], evaluated the impact of amantadine on cognition in a male $35 \mathrm{y}$ who had been assaulted to the head with a blunt object. The patient presented with a GCS score of 3, the patient showed improvement at a dose of $400 \mathrm{mg} /$ day. The patient was rehabilitated to become independent in his activities of daily living.

\begin{tabular}{lllllll}
\multicolumn{2}{c}{ 2nd week } & \multicolumn{5}{c}{ Month } \\
\hline 1st 3ds & 2nd 3ds & M1 & M2 & M3 & M4 & M5 \\
\hline 7.89 & 8.57 & $9.44 \pm$ & $10.5 \pm$ & 10.93 & 11.18 & 11.81 \\
\pm 2.68 & \pm 3.11 & 3.34 & 3.24 & \pm 3.39 & \pm 3.48 & \pm 3.41 \\
6.64 & 7.07 & $7.92 \pm$ & $8.5 \pm$ & $8.85 \pm$ & $9.07 \pm$ & $9.28 \pm$ \\
\pm 1.21 & \pm 1.59 & 2.43 & 3.25 & 3.69 & 3.89 & 3.97 \\
6.14 & 6.46 & $7.15 \pm$ & $8 \pm$ & $8.38 \pm$ & $8.69 \pm$ & $8.84 \pm$ \\
\pm 1.91 & \pm 1.80 & 2.51 & 3.58 & 3.90 & 3.92 & 4.01 \\
0.091 & 0.077 & 0.089 & $0.028^{*}$ & $0.031^{*}$ & $0.047^{*}$ & $0.048^{*}$ \\
0.064 & 0.063 & $0.024^{*}$ & $0.003^{*}$ & $0.003^{*}$ & $0.010^{*}$ & $0.009^{*}$ \\
0.893 & 0.909 & 0.608 & 0.530 & 0.530 & 0.608 & 0.569 \\
\hline
\end{tabular}

p2: Comparison between GI \& GIII. p3: Comparison between GII \& GIII.

Table (7): Total number of complication in three groups.

\begin{tabular}{llllll}
\hline Complication & $\begin{array}{c}\text { Group } \\
\text { I }\end{array}$ & $\begin{array}{c}\text { Group } \\
\text { II }\end{array}$ & $\begin{array}{c}\text { Group } \\
\text { III }\end{array}$ & $\chi^{2}$ & $\begin{array}{c}p- \\
\text { value }\end{array}$ \\
\hline Seizures & $2(10 \%)$ & 0 & $1(5 \%)$ & 2.105 & 0.3490 \\
Deep vein thrombosis & 0 & $1(5 \%)$ & 0 & 2.034 & 0.3617 \\
Pulmonary Embolism & 0 & 0 & 0 & & \\
Deaths & $4(20 \%)$ & $6(30 \%)$ & $7(34 \%)$ & 1.149 & 0.5630 \\
\hline
\end{tabular}

Also, Silver et al., [13], reported a female 82 years with improved ability to function after use of amantadine for TBI. She remained unresponsive after a motor car accident with a GCS of 6 for 3 days before the use of amantadine. After 6 doses of amantadine $150 \mathrm{mg}$ bid, she could withdraw from pain, open her eyes spontaneously, and respond to her name. By day 7, she was alert and oriented. Also, Sawyer et al., [14], improvements in arousal and cognition have been observed in patients with TBI when amantadine has been initiated 3 days to 5 months after injury. At doses of 200-400mg/day [14].

Similarly, Nickels et al., [15], describe a patient who following a TBI suffered frontal lobe dysfunction and became agitated. Amantadine was initiated following failure to respond to neuroleptic and anxiolytic therapy. Improvement was noticed at doses of $100 \mathrm{mg}$ orally twice daily. Also, Saniova 
et al., [16], concluded that 74 patients with severe head injury (GCS $<8$ ) were divided into two groups, in ${ }^{1 \text { st }}$ group amantadine was started 3 days post trauma in 41 patients at a dose of $200 \mathrm{mg}$ bid. The level of consciousness has improved in 39, the average initial GCS in this group was $4.74 \pm 2.26$ and the average outcome GCS of the surviving patients was $9.76 \pm 3.95$.

Also, Giacino et al., [17], they concluded that in the group of patients with severe brain injuries treated with standard therapy plus Amantadine Sulphate the outcome GCS was higher and the case fatality rate lower than in the group treated with standard therapy alone.

Moreover, Hughes et al., [18], 123 patients with severe head injury (GCS less than 8 ) were divided into two groups, $46 \%$ of patients in amantadine group showed emergence from coma while only $38 \%$ of patients in placebo group showed emergence.

Additionally, Meythaler et al. [19] conducted a double-blind, randomized, placebo-controlled, crossover, pilot trial to assess the use of amantadine in both early and late phases of TBI. The authors concluded that amantadine appeared to be effective in improving cognition following TBI, independent of timing of administration.

In contrary to our results, Harun et al. [20] concluded that Amantadine has no effect on recovery of consciousness; it remains safe, inexpensive and has few side effects.

In agreement with our results as regard neuroprotective effect of Erythropoietin, Nirula et al. [21]found that Intravenous EPO was well tolerated in diffuse axonal injury and was associated with an improvement in patients' outcome in 2 weeks.

In accordance with our results, Zhang et al. [22]found that EPO administration has been found to improve motor, sensory and cognitive function in experimental TBI and has also been shown to reduce lesion size and cell death after injury.

In contrary to our result, Nichol et al., [23] in a large RCT, compared with placebo, erythropoietin did not reduce the proportion of patients with a poor outcome (death, vegetative state, and severe disability): 134 (44\%) of 302 patients in the erythropoietin group vs. $132(45 \%)$ of 294 in the placebo group.

Also, Robertson et al., [24] concluded that in patients with closed head injury, neither the admin- istration of erythropoietin nor maintaining hemoglobin concentration of greater than $1 \mathrm{Og} / \mathrm{dL}$ resulted in improved neurological outcome at 6 months. The transfusion threshold of $10 \mathrm{~g} / \mathrm{dL}$ was associated with a higher incidence of adverse events.

In our current study, both groups, Amantadine group and Erythropoietin group show improvement in conscious level guided by comparing the results of DRS at day 1 (baseline) and after five months. These results are consistent with our results of Glasgow coma scale.

This improvement is consistent with Giacino et al., [17], which was a multicenter, randomized and controlled trial. During the 4-weeks treatment period, recovery was significantly faster in the amantadine group than in the placebo group, as measured by the DRS score ( $p=0.007)$, indicating a benefit with respect to the primary outcome measure. Also, in agreement with our results, Whyte et al., [25],concluded that Amantadine treatment significantly associated with improved DRS when measured week to week.

Only one study Schneider et al., [3] suggests that no significant difference in rates of improvement for patients receiving placebo versus amantadine.

In the current study, as regard to length of mechanical ventilation, there was no statistically significant difference between the three groups ( $p$ value $<0.05$ ), but it was shorter in Group I compared to Group II and III. As regard to length of SICU stay and length of hospital stay, the mean values showed that there were statistically shorter ( $p$ value $<0.05$ ) in Group I compared to Group II and III. In agreement with our results, Hughes et al., [18], included 123 adults with severe Traumatic Brain Injury (TBI) admitted over a 10-year period who remained in coma despite becoming medically stable. Cases received 100-200mg of amantadine twice daily. Main outcomes and results: $46.4 \%$ $(13 / 28)$ of cases emerged from coma compared to $37.9 \%(36 / 95)$ of controls $(p=0.42)$.

In agreement with our results, Saniova et al. [16] 74 patients with severe head injury $($ GCS $<8)$ were divided into two group, in 1 group amantadine was started 3 days post trauma in 41 patients at a dose of $200 \mathrm{mg}$ bid, the level of consciousness has improved in 39, patients after regaining consciousness were transferred to other departments. Mean hospitalization time of the patients was 8.36 days. In placebo group, there were 33 patients, mean hospitalization time was 9.36 days. 
In our study, seizures occurred in $10 \%$ of the patients ( 2 patients) in Group I as compared to 5\% of the patients ( 1 patient) in Group III. There were no seizures in Group II. There were no significant differences among three groups ( $p$-value $<0.05$ ). In agreement with our results, Nickels et al. [15] identified 12 patients with heterogeneous brain injury treated with amantadine. Neurobehavioral and cognitive status were assessed before, during and after amantadine therapy. Significant sideeffects were recorded as well. Three patients were started on amantadine due to agitation in a dose of 50 to $100 \mathrm{mg}$ orally twice daily without any side effects. The remaining nine patients began amantadine therapy for low-arousal in a dose of $200 \mathrm{mg}$ orally twice daily. Eight of these nine patients showed improvements in cognitive and/or physical function. Approximately half of the subjects experienced side-effects possibly related to amantadine. Side-effects ranged from hypomania $(100 \mathrm{mg}$ orally twice daily) to generalized seizures (150 and $200 \mathrm{mg}$ orally twice daily). The exact relationship of these side-effects to amantadine is unclear.

Deep vein thrombosis occurred in only 1 patient (5\% of the patients) in Group II. There was no DVT in Group I \& III.

There was no pulmonary embolism in the three studied groups.

Many concerns have been raised about the ability of EPO to increase the risk of Venous Thromboembolism (VTE). The United States Food and Drug Administration recently added a black box warning regarding this risk on EPO preparations [23]

In agreement with our results, Robertson et al., [24], found that the incidence of thromboembolic events was examined because a higher overall incidence was observed with the transfusion threshold of $10 \mathrm{~g} / \mathrm{dL}$ and a higher incidence of upper extremity Deep Venous Thrombosis (DVT) was found in the groups treated with erythropoietin. During the 6 months of follow-up of 200 patients, 25 (12.5\%) developed DVT, 4 patients had multiple thromboembolic events. Pulmonary embolus occurred in none of the patients in the erythropoietin group.

As regard mortality rate, 4 patients died in Group I (20\%), 6 patients in Group II (30\%) and 7 patients in Group III (34\%). There were no significant differences among the three groups. In agreement with our results, Saniova et al., [16], 74 patients with severe head injury (GCS $<8$ ) were divided into two group, in 1 group Amantadine was started 3 days post trauma in 41 patients at a dose of $200 \mathrm{mg}$ bid, only two patients died in this group $(6.06 \%)$. In placebo group, 17 patients died $(51.51 \%)$.

Also, Laureys et al. [5] concluded that in the group of patients with severe brain injuries treated with standard therapy plus amantadine sulphate the outcome GCS was higher and the case fatality rate lower than in the group treated with standard therapy alone.

\section{Conclusions:}

We found that in the group of patients with severe brain injuries treated with standard therapy plus Amantadine Sulphate, consciousness was better, the case fatality rate was lower and length of mechanical ventilation, SICU stay and hospital stay were shorter than in the group treated with standard therapy plus Erythropoietin and the group treated with standard therapy only. We concluded that using of Amantadine Sulphate is better than using of Erythropoietin for improving neurorecovery on Traumatic Brain Injury (TBI), also we concluded that Erythropoietin is a potentially useful treatment option for TBI but confirmatory evidence is required for that and for the ability of EPO to increase the risk of Venous Thromboembolism (VTE).

\section{Conflicts of interest:}

No conflicts of interest declared.

\section{Authors' contributions:}

All authors had equal role in design, work, statistical analysis and manuscript writing.

\section{References}

1- FAUL M., XU L., WALD M.M. and CORONADO V.: Traumatic brain injury in the United States. Atlanta, G.A.: National Center for Injury Prevention and Control, Centers for Disease Control and Prevention, 2010.

2- SAATMAN K.E., DUHAIME A.C., BULLOCK R., MAAS A.I., VALADKA A. and MANLEY G.T.: Classification of traumatic brain injury for targeted therapies. Journal of Neurotrauma, 25 (7): 719-38, 2008.

3- SCHNEIDER J.D.C., TONY M. WONG, MARY L. DOMBOVY and WILLIAM N.: Cognitive and behavioural efficacy of amantadine in acute traumatic brain injury: An initial double-blind placebo-controlled study. Brain Injury, 13 (11): 863-72, 2002.

4- TENOVUO O.: Pharmacological enhancement of cognitive and behavioral deficits after traumatic brain injury. Current opinion in neurology, 19 (6): 528-33, 2006.

5- GIACINO J.T., FINS J.J., LAUREYS S. and SCHIFF N.D.: Disorders of consciousness after acquired brain injury: The state of the science. Nature Reviews Neurology, 10 (2): 99-114, 2014 
6- BRINES M.L., GHEZZI P., KEENAN S., AGNELLO D., De LANEROLLE N.C., CERAMI C., et al.: Erythropoietin crosses the blood-brain barrier to protect against experimental brain injury. Proceedings of the National Academy of Sciences, 97 (19): 10526-31, 2000.

7- PONCE L.L., NAVARRO J.C., AHMED O. and ROBERTSON C.S.: Erythropoietin neuroprotection with traumatic brain injury. Pathophysiology, 20 (1): 31-8, 2013.

8- EAPEN B.C. and CIFU D.X.: Traumatic Brain Injury Rehabilitation, An Issue of Physical Medicine and Rehabilitation Clinics of North America, E-Book: Elsevier Health Sciences, 2017.

9- CHUA K.S., NG Y., YAP S.G. and BOK C.: A brief review of traumatic brain injury rehabilitation. Annals-Academy of Medicine Singapore, 36 (1): 31, 2007.

10- DAWSON R., FINTEL N.V. and NAIRN S.: Sedation assessment using the Ramsay scale: Rachel Dawson and colleagues review the reliability of tools for assessing sedation and how these differ from methods of measuring consciousness. Emergency Nurse, 18 (3): 18-20, 2010.

11- WILSON J.L., PETTIGREW L.E. and TEASDALE G.M.: Structured interviews for the Glasgow Outcome Scale and the extended Glasgow Outcome Scale: Guidelines for their use. Journal of neurotrauma, 15 (8): 573-85, 1998.

12- GORDON W.A., ZAFONTE R., CICERONE K., CANTOR J., BROWN M., LOMBARD L., et al.: Traumatic brain injury rehabilitation: state of the science. American Journal of Physical Medicine \& Rehabilitation, 85 (4): 343-82, 2006.

13- SILVER J.M., HALES R.E. and YUDOFSKY M.: Neuropsychiatric aspects of traumatic brain injury. Essentials of Neuropsychiatry and Behavioral Neurosciences, 22374, 2010.

14- SAWYER E., MAURA L. S. and OHLINGER M.J.: Amantadine enhancement of arousal and cognition after traumatic brain injury. Annals of Pharmacotherapy, 42 (2): 247-52, 2008.

15- NICKELS J., SCHNEIDER W., DOMBOVY M.L. and WONG T.: Clinical use of amantadine in brain injury rehabilitation. Brain Injury, 8 (8): 709-18, 2006.

16- SANIOVA B., DROBNY M., KNESLOVA L. and MINARIK M.: The outcome of patients with severe head injuries treated with amantadine sulphate. Journal of Neural Transmission, 111 (4): 511-4, 2004.
17- GIACINO J.T., WHYTE J., BAGIELLA E., KALMAR K., CHILDS N., KHADEMI A., et al.: Placebo-controlled trial of amantadine for severe traumatic brain injury. New England Journal of Medicine, 366 (9): 819-26, 2012.

18- HUGHES S., COLANTONIO A., SANTAGUIDA P.L. and PATON T.: Amantadine to enhance readiness for rehabilitation following severe traumatic brain injury. Brain Injury, 19 (14): 1197-206, 2005.

19- MEYTHALER J.M., BRUNNER R.C., JOHNSON A and NOVACK T.A.: Amantadine to improve neurorecovery in traumatic brain injury-associated diffuse axonal injury: A pilot double-blind randomized trial. The Journal of Head Trauma Rehabilitation, 17 (4): 300-13, 2002.

20- HARUN R. and WAGNER A.K.: The neurobiological basis of pharmacological approaches for patients with traumatic brain injury. Understanding Traumatic Brain Injury: Current Research and Future Directions, 255, 2014.

21- NIRULA R., DIAZ-ARRASTIA R., BRASEL K., WEIGELT J. and WAXMAN K.: Safety and efficacy of erythropoietin in traumatic brain injury patients: A pilot randomized trial. Critical Care Research and Practice. 2010, 2010.

22- ZHANG Y., XIONG Y., MAHMOOD A., MENG Y., QU C., SCHALLERT T., et al.: Therapeutic effects of erythropoietin on histological and functional outcomes following traumatic brain injury in rats are independent of hematocrit. Brain research, 1294: 153-64, 2009.

23- NICHOL A., FRENCH C., LITTLE L., HADDAD S., PRESNEILL J., ARABI Y., et al.: Erythropoietin in traumatic brain injury (EPO-TBI): A double-blind randomised controlled trial. The Lancet, 386 (10012): 2499506, 2016 .

24- ROBERTSON C.S., HANNAY H.J., YAMAL J.M., GOPINATH S., GOODMAN J.C., TILLEY B.C., et al.: Effect of erythropoietin and transfusion threshold on neurological recovery after traumatic brain injury: A randomized clinical trial. Jama., 312 (1): 36-47, 2014.

25- WHYTE J., KATZ D., LONG D., DiPASQUALE M.C., POLANSKY M., KALMAR K., et al.: Predictors of outcome in prolonged posttraumatic disorders of consciousness and assessment of medication effects: A multicenter study. Archives of physical medicine and rehabilitation, 86 (3): 453-62, 2005. 


\section{دراسة مقارنة بين فاعلية آمانتادين سيلفات مقابل آريثروبيوتين على إصابات الرآس}

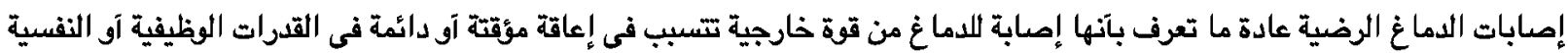

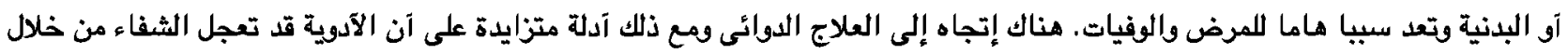

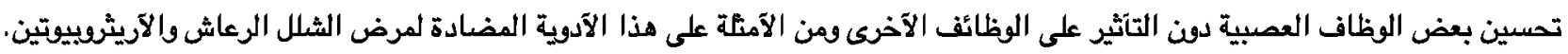

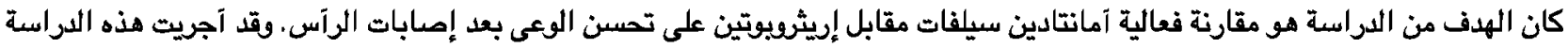

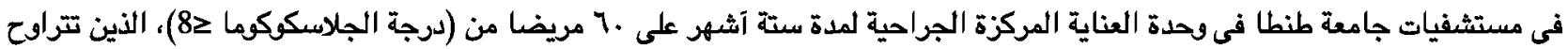

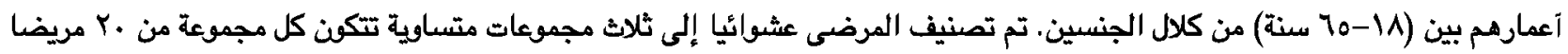

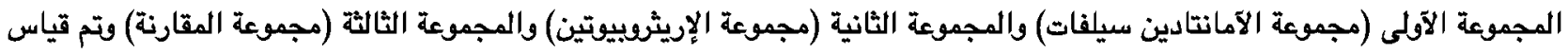
درجة الجلاسكوكما ومقياس تصنيف الإعاقة ومقياس السككن وطول فترة بقاء المريض على جهاز التنفس الصناعى طول فترة البقاء في العناية

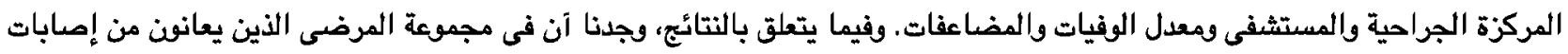

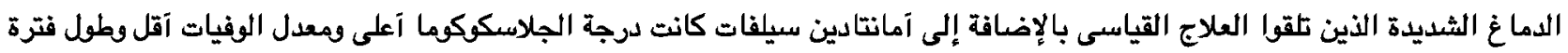

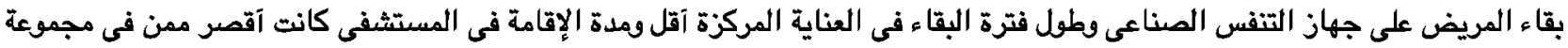

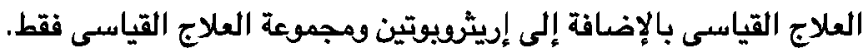

